\title{
Modeling and Analysis of Thermal Flexure Actuator Using COMSOL Multiphysics
}

\author{
Girija M. Nimbal, S. V. Halse, R. S. Mathad, B. Jyoti, and Rafia Begum
}

\begin{abstract}
Thermal actuators are extensively used in microelectromechanical systems (MEMS). Heat transfer through and around these microstructures are very complex. Knowing and controlling them in order to improve the performance of the micro-actuator, is currently a great challenge. This paper deals with this topic and proposes a dynamic thermal modeling of thermal micro-actuators. Actuator deflection is computed based on elastic analysis of structures. The model predicts the performance of a polysilicon thermal flexure actuator has been developed. The thermal actuators are designed using Thermal stress in Structural mechanics of COMSOL Multiphysics 4.3. The result of modulation and analysis shows the better displacement for the temperature ranges. Actuator deflection is computed based on elastic analysis of structures. Varying the applied voltage and geometrical dimension gives a clear understanding about the performance of the structure.
\end{abstract}

Index Terms-MEMS, actuators, thermal analysis, modeling FEM.

\section{INTRODUCTION}

Guckel et al. [1] proposed a topology for electro thermally actuated microactuator, which has been developed extensively by Comtois and Bright [2]-[4]. The basic two are electron thermal actuator design uses the principle of Joule heating for thermal expansion and movement. The two arm actuator design consists of a thin arm, wide arm and flexure arm connected together at one end and constrained elastically at the anchors. The layers density in the thin arm causes a greater thermal expansion than that in the wide arm. In previous research on design of these devices for maximum deflection and force, hickey [5] has laid down guidelines for optimization using a trial and error analytical approach. Chen et al. [6] have investigated the effect by analyzing various actuator designs using semi analytical approach. This study presents the analytical and FEM modeling to explain the behavior of the designed thermal actuators. Commercial MEMS software, COMSOL Multiphysics 4.3 is used for FEM modeling and analysis. The aim of this study is to analyze the temperature distribution and the expected

Manuscript received February 6, 2014; revised April 27, 2014

Girija M. Nimbal is with Department of Electronics, Karnataka State Women's University, Bijapur, India (e-mail: girija_mnimbal@yahoo.com).

S. V. Halse is with Registrar Evaluation, Gulbarga University, Gulbarga (e-mail: drsvhalse@rediffmail.com).

R. S. Mathad is with Department of Electronics, Basavewhar Science Degree Collage, Bagalkot, India (e-mail: rmathad@gmail.com).

B. Jyoti is with Department of Electronics, Bibi Razak Degree College, Gulbarga, India (e-mail: bjyoti1967@gmail.com).

Rafia Begum is with the Department of E and E Governrnment Polytechnique Bijapur, India (e-mail: begumrafiya86@gmail.com). deflection from the thermal microactuator. Finally, the effect of the certain important parameters such as applied voltage and geometrical dimension of the thermal actuator are investigated.

\section{METHODOLOGY}

The actuator is activated through thermal expansion. The temperature increase required to deform the two hot arms and thus displace the actuator is obtained through Joule heating The greater expansion of the hot - arms compared to the cold arm which causes a bending of the actuator. The actuators operation thus involves three coupled physics phenomena electric current conduction, heat conduction with heat generation, and structural stresses and strains due to thermal expansion then selecting boundary conditions and constraints after that the electric potential is applied between the bases of the hot arms anchors. The cold arm anchor and all other surface are electrically insulated. The temperature of the base of the three anchors and the three dimples is fixed to that of the substrates constant temperature. Then boundaries are interacting with thin layers of air. Here all three arms are mechanically fixed at the base of the three anchors. The dimples can move freely in the plane of the $X Y$ - plane but not move in the direction perpendicular to the $Z$ - direction.

\section{THEORY}

There are three mechanisms of heat flow: conduction, convection and radiation. According to previous research [7], the heat dissipation through radiation to the ambient can be neglected in comparison with the heat losses through conduction to the anchors which are considered as heat sinks and the heat losses through air to the substrate due to convection. When the heat transfer flow is under steady-state conditions, resistive heating power generated in the element is equal to the heat conduction and convection out of the element:

$$
\begin{gathered}
-k_{p} w h\left(\frac{d T}{d x}\right)_{x}+J^{2} \rho w t d \\
=-k_{p} w h\left(\frac{d T}{d x}\right)_{x+d x}+\frac{S w\left(T-T_{s}\right) d x}{R_{T}}
\end{gathered}
$$

where $T, T_{s}$ are the temperature of the beam and the substrate, respectively, $k_{p}$ is the thermal conductivity of polysilicon, $J$ is the current density, $\rho$ is the resistivity of polysilicon, and $S$ is the shape factor which accounts for the impact of the shape of 
the element on heat conduction to the substrate. This geo-metric factor represents the ratio of heat loss from the sides and bottom of the beam to the heat loss from the bottom of the beam only. $R_{T}$ is the thermal resistance between the poly-silicon microbeam and the substrate if the microbeam were wide enough. The thermal resistance is given by

$$
R_{T}=\frac{t_{v}}{k_{v}}+\frac{t_{n}}{k_{n}}
$$

where $t_{v}$ and $t_{n}$ are the elevation of the hot arm above the $\mathrm{Si} 3 \mathrm{~N} 4$ and the thickness of Si3N4 respectively and $k_{v}, k_{n}$ are the thermal conductivity of the air. The shape factor is given by [8]

$$
S=\frac{h}{w}\left(\frac{2 t_{v}}{h}+1\right)+1
$$

Usually, the resistivity of polysilicon, $\rho$, is related to temperature. The resistivity is assumed here to have a linear temperature coefficient, $\xi$, such that $\rho\left(T_{s}\right)=\rho_{o}$, that is,

$$
\begin{gathered}
\rho(T)=\rho_{o}\left[1+\xi\left(T-T_{s}\right)\right] \\
J=\frac{V^{2}}{\rho L}
\end{gathered}
$$

where $V$ is voltage across the arm and $L$ is the length of the hot arm. Taking the limit as $\Delta x \rightarrow 0$, equation (1) is simplified to

$$
\frac{d^{2} T(x)}{d x^{2}}=\frac{S\left(T-T_{s}\right)}{R_{T} k_{p} h}-\frac{J^{2} \rho}{k_{p}}
$$

Substitute equation (4) and (5), and using the Taylor series expansion to make linear the resistive heating power term [4], the equation (6) becomes:

$$
\begin{gathered}
\frac{d^{2} T(x)}{d x^{2}}=\frac{S\left(T-T_{s}\right)}{R_{t} k_{p} h}-\frac{V^{2}}{L^{2} \rho_{o}}\left[1-\xi\left(T-T_{s}\right)\right] \\
\frac{d^{2} T_{\theta}}{d x^{2}}=A^{2} T_{\theta}-B \\
T_{\theta}=T-T_{s} \\
B=\frac{V^{2}}{L^{2} \rho_{o} k_{p}} \\
A^{2}=\frac{S}{R_{T} k_{p} h}+B \xi
\end{gathered}
$$

The solution for the linear differential equation (8) is

$$
T_{h}(x)=T_{s}+\frac{B}{A^{2}}+c_{1} e^{A x}+c_{2} e^{-A x}
$$

For the boundary conditions, it can be assumed that the anchor pad has the same temperature as the substrate, $T_{s}$, and the temperature at the interface section is maximal, that

$$
\begin{gathered}
T_{h}(0)=T_{s} \\
\frac{d T(x)}{d x}(x=L)=0
\end{gathered}
$$

Solving equation (10), (11) and (12) gives the temperature distribution along the hot arm is:

$$
T_{h}(x)=T_{s}+\frac{B}{A^{2}}-\frac{B}{A^{2}} \times \frac{1}{1+e^{-2 A L}}\left(e^{-A L} e^{A x}+e^{-A x}\right)
$$

The maximum temperature is at the interface section is

$$
T_{m}=T_{s}+\frac{B}{A^{2}}-\frac{B}{A^{2}} \times \frac{2 e^{-A L}}{1+e^{-2 A L}}
$$

The linear expansion for hot arm is

$$
\Delta L_{h}=\alpha \int_{0}^{L}\left(T_{h}(x)-T_{s}\right) d x=\alpha L\left(\overline{T_{h}-T_{s}}\right)
$$

where is the average temperature of the hot arm.

$$
\begin{aligned}
& \overline{T_{h}}=T_{s}+\frac{B}{A^{2}}-\frac{B}{A^{2}} \times \frac{e^{-2 A L}}{\left(1+e^{-2 A L}\right) \times A L}\left(\mathrm{e}^{A L}-1\right)+ \\
& \frac{B}{A^{2}} \times \frac{1}{\left(1+e^{-2 A L}\right) \times A L}\left(e^{-A L}-1\right)
\end{aligned}
$$

The radiant energy received by the cold arm from the hot ones may be approximately written by [5]

$$
E_{h c}=\sum_{t=1}^{2} h L_{c} F_{i} \varepsilon \rho\left(\overline{T_{h}^{4}-T_{s}^{4}}\right)
$$

where $\varepsilon$ is the effective absorptive of poly silicon, $\sigma$ is the Stefan - Boltzman and $F_{i}(i=1 \ldots 6)$ is the radiation shape factor corresponding to six hot arms [9]-[11].

$$
\begin{aligned}
& F_{i}=\frac{2}{\Pi X_{i} Y_{i}}\left[\ln \sqrt{\frac{\left(1+X_{i}^{2}\right)\left(1+Y_{i}^{2}\right)}{1+X_{i}^{2}+Y_{i}^{2}}}\right]+ \\
& X_{i} \sqrt{1+Y_{i}^{2}} \tan ^{-1}\left(\frac{X_{i}}{\sqrt{1+Y_{i}^{2}}}\right)+Y_{i} \sqrt{1+X_{i}^{2}} \tan ^{-1}\left(\frac{Y_{i}}{\sqrt{1+X_{i}^{2}}}\right) \\
& -X_{i} \tan ^{-1}\left(X_{i}\right)-Y_{i} \tan ^{-1}\left(Y_{i}\right)
\end{aligned}
$$


where $X_{i}=\frac{h}{g_{i}}$ and $Y_{i}=\frac{L_{c}}{g_{i}}$, and $g_{i}$ is the distance from the $i_{\text {th }}$ hot arm to cold arm.

\section{SETTING BOUNDARY CONDITIONS}

The heat flux boundary condition for the convection to the substrate in COMSOL has to be given in the Input form for heat boundary condition [13], this means that in the expression of inward heat flux the coefficient $h$ must be written as:

$$
h=\frac{S}{R_{T}}
$$

The Joule-heating model window is shown on the Fig. 1 and Fig. 2.

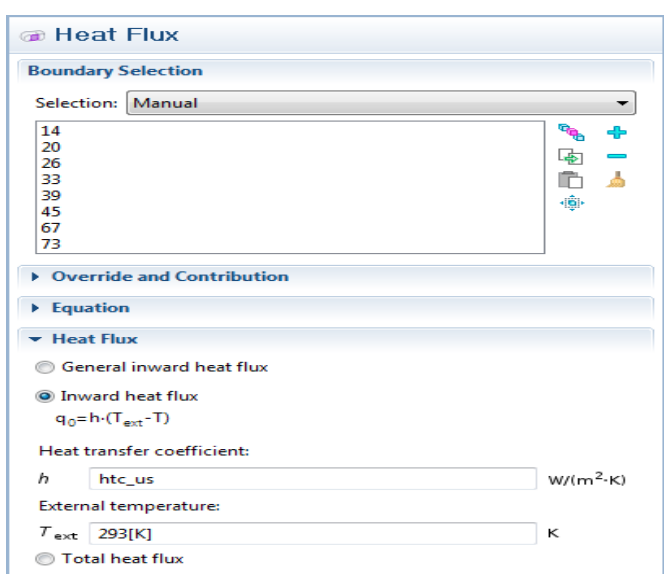

Fig. 1. Input form for heat boundary condition.

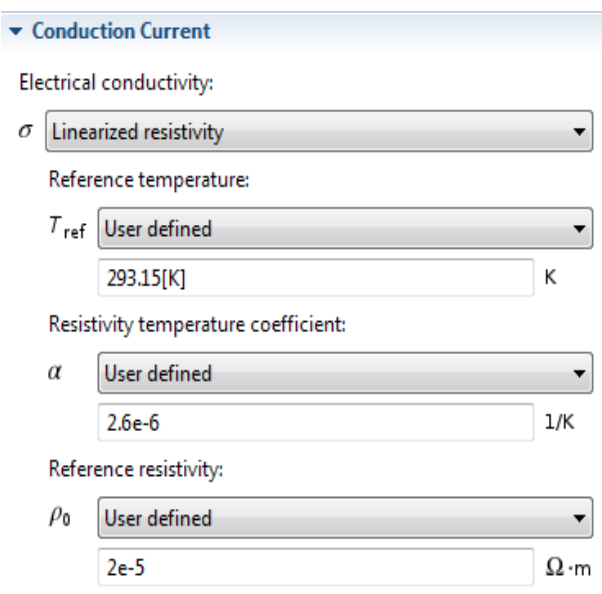

Fig. 2. Temperature dependent resistivity setting.

\section{PERformance Analysis}

TABLE I: APPLIED VOLTAGE V/S MAXIMUM TEMPERATURE

\begin{tabular}{|l|c|c|}
\hline & \multicolumn{2}{|c|}{ Actuator Length $\mathbf{2 4 0} \boldsymbol{\mu m}$} \\
\hline Sl. No & Applied Voltage & $\begin{array}{c}\text { Maximum } \\
\text { Temperature(K) }\end{array}$ \\
\hline 1 & 0 & 600.92 \\
\hline 2 & 2 & 653.94 \\
\hline 3 & 4 & 700.92 \\
\hline 4 & 6 & 740.92 \\
\hline 5 & 8 & 800.92 \\
\hline 6 & 10 & 850.92 \\
\hline
\end{tabular}

\begin{tabular}{|l|c|c|}
\hline & \multicolumn{2}{|c|}{ Actuator Length $200 \boldsymbol{\mu m}$} \\
\hline Sl.No & Applied Voltage & $\begin{array}{c}\text { Maximum } \\
\text { Temperature(K) }\end{array}$ \\
\hline 1 & 0 & 500.92 \\
\hline 2 & 2 & 550.72 \\
\hline 3 & 4 & 576.72 \\
\hline 4 & 6 & 600.72 \\
\hline 5 & 8 & 650.62 \\
\hline 6 & 10 & 750.82 \\
\hline
\end{tabular}

\begin{tabular}{|l|c|c|}
\hline & \multicolumn{2}{|c|}{ Actuator Length $\mathbf{1 8 0} \boldsymbol{\mu m}$} \\
\hline Sl.No & Applied Voltage & $\begin{array}{c}\text { Maximum } \\
\text { Temperature(K) }\end{array}$ \\
\hline 1 & 0 & 400.85 \\
\hline 2 & 2 & 450.85 \\
\hline 3 & 4 & 500.75 \\
\hline 4 & 6 & 550.75 \\
\hline 5 & 8 & 600.75 \\
\hline 6 & 10 & 650.92 \\
\hline
\end{tabular}

TABLE II: DIFFERENT ACTUATOR LENGTH WITH OBTAINED STRESS

TABLE II: DIFFERENT ACTUATOR LENGTH WITH OBTAINED STRESS
\begin{tabular}{|c|c|c|}
\hline & \multicolumn{2}{|c|}{ Actuator Length $\mathbf{2 4 0} \boldsymbol{\mu m}$} \\
\hline Sl.No & Applied Voltage & Obtained Stress \\
\hline 1 & 0 & 0.28 \\
\hline 2 & 2 & 0.31 \\
\hline 3 & 4 & 0.35 \\
\hline 4 & 6 & 0.36 \\
\hline 5 & 8 & 0.4 \\
\hline 6 & 10 & 0.5 \\
\hline
\end{tabular}

\begin{tabular}{|l|c|c|}
\hline & \multicolumn{2}{|c|}{ Actuator Length 200 $\boldsymbol{\mu m}$} \\
\hline Sl.No & Applied Voltage & Obtained Stress \\
\hline 1 & 0 & 0.15 \\
\hline 2 & 2 & 0.2 \\
\hline 3 & 4 & 0.22 \\
\hline 4 & 6 & 0.25 \\
\hline 5 & 8 & 0.26 \\
\hline 6 & 10 & 0.35 \\
\hline
\end{tabular}

\begin{tabular}{|l|c|c|}
\hline & \multicolumn{2}{|c|}{ Actuator Length $\mathbf{1 8 0} \boldsymbol{\mu m}$} \\
\hline Sl.No & Applied Voltage & Obtained Stress \\
\hline 1 & 0 & 0.08 \\
\hline 2 & 2 & 0.12 \\
\hline 3 & 4 & 0.15 \\
\hline 4 & 6 & 0.17 \\
\hline 5 & 8 & 019 \\
\hline 6 & 10 & 0.2 \\
\hline
\end{tabular}

TABLE III: OBTAINED TEMPERATURE VS OUTER \& INNER ACTUATOR ARMS (MICRO BEAMS)

\begin{tabular}{|c|c|c|c|}
\hline \multicolumn{4}{|c|}{ Actuator Length 240 $\boldsymbol{\mu m}$} \\
\hline SI.No & Obtained Temp & Outer Actuator & $\begin{array}{c}\text { Inner } \\
\text { Actuator }\end{array}$ \\
\hline 1 & 550 & 2.373 & 2.376 \\
\hline 2 & 600 & 2.377 & 2.378 \\
\hline 3 & 640 & 2.401 & 2.397 \\
\hline 4 & 710 & 2.393 & 2.391 \\
\hline 5 & 900 & 2.386 & 2.386 \\
\hline 6 & 1200 & 2.382 & 2.377 \\
\hline
\end{tabular}

\begin{tabular}{|l|l|l|l|}
\hline & \multicolumn{3}{|c|}{ Actuator Length $200 \mu \mathrm{m}$} \\
\hline SI.No & Obtained Temp & Outer Actuator & $\begin{array}{c}\text { Inner } \\
\text { Actuator }\end{array}$ \\
\hline 1 & 490 & 1.975 & 1.979 \\
\hline 2 & 510 & 1.982 & 1.988 \\
\hline 3 & 550 & 1.997 & 1.991 \\
\hline 4 & 750 & 1.983 & 1.979 \\
\hline 5 & 1000 & 1.981 & 1.973 \\
\hline 6 & 1400 & 1.977 & 1.969 \\
\hline
\end{tabular}




\begin{tabular}{|l|l|l|l|}
\hline & \multicolumn{3}{|c|}{ Actuator Length 180 $\boldsymbol{\mu m}$} \\
\hline SI.No & Obtained Temp & Outer Actuator & $\begin{array}{c}\text { Inner } \\
\text { Actuator }\end{array}$ \\
\hline 1 & 370 & 1.777 & 1.783 \\
\hline 2 & 430 & 1.837 & 1.837 \\
\hline 3 & 550 & 1.784 & 1.782 \\
\hline 4 & 780 & 1.773 & 1.776 \\
\hline 5 & 850 & 1.763 & 1.765 \\
\hline 6 & 900 & 1.752 & 1.755 \\
\hline
\end{tabular}

\section{RESULT}

As we away from the thermal actuator intensification goes on reducing as seen from the white red yellow in Fig. 6-Fig. 8 with applying different voltage and temperatures then applying as parameter that is heat transfer coeffiecit is $0.04[\mathrm{~W} / \mathrm{m} * \mathrm{k}] / 2[\mathrm{um}]$ with different applied actuator lengths, for this actuator using mechanical properties are, Polysilicon, Si3N4 and Air is used. Table I shows the original performance of thermal actuator i.e. Applied voltages VS Maximum Temperature with different actuator length. Table II shows the Actuator length VS Obtained stress for applied voltage 10 the obtained stress is 0.35 . Fig. 3-Fig. 5 show its points. The reduced maximum temperature for any applied voltage which is contributed by the change in the gap the width of the wide arm and flexure arm length. Since the deflection is minimized the significant papers that effect the force output from the thermal actuator area decrease in the actuator length increase in the width of the thin arm decrease in the width of the wide arm and increase in the thin arm .
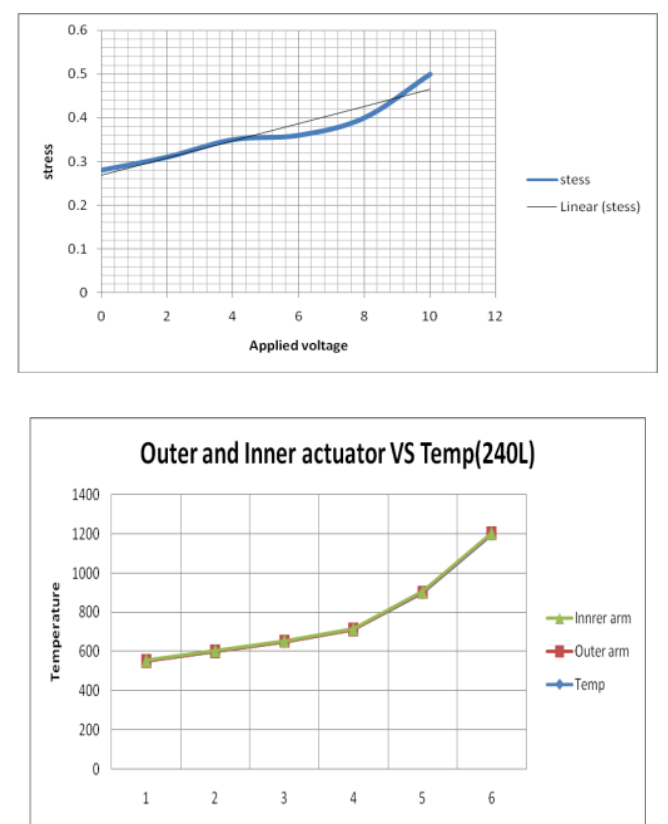

Fig. 3. (a) Applied voltage vs stress graph(length 240), (b) Outer and inner actuator VS temperature.

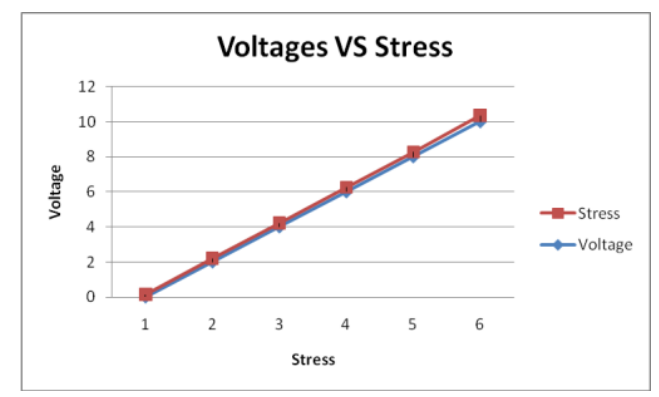

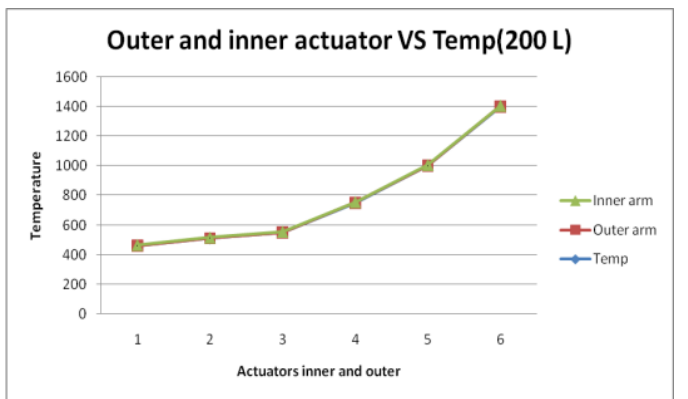

Fig. 4. (a) Applied voltages vs stress graph(length200), (b) Outer and inner actuator VS temperature.
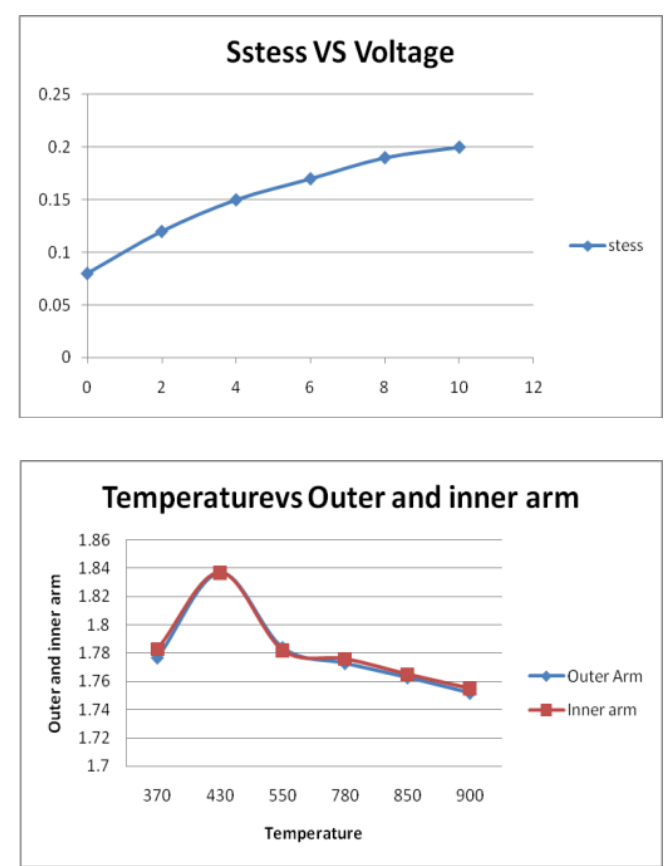

Fig. 5. (a) Applied voltages vs stress graph (length180) (b) Outer and inner actuator VS temperature.

\section{CONCLUSION}

The Analysis of thermal actuator gave a considerable difference comparing to the analytic model. It is because of the heat conduction for the shunt at the end of the beam was not included in the model and the simplified model does not include heat conduction between hot-beams. This difference of the results shows the advantage of using COMSOL Multiphysics, \& FEM software. The maximal temperature values indicate that only the actuator designs with results armed with White Red \& Yellow colour in Fig. 6-Fig. 8 also in Table I to Table III can be used if $700.92 \mathrm{~K}$ is set as maximal temperature for the actuator. The deflection value obtained for the loaded beam, length of $240 \mu \mathrm{m}, 200 \mu \mathrm{m}$ and $180 \mu \mathrm{m}$, at $10 \mathrm{~V}$ driving voltage. In further work an analytic model for the load arising from the polysilicon flexure and thermal actuator plate should be designed. In general this work made us to become familiar with FEM simulation in heat conduction domain using COMSOL and also made aware us about difficulties to build an appropriate analytic model. Thermal actuators have been measured and compared with the results of the theoretical model. The theoretical model presented would therefore find applications in the design and optimization of polysilicon thermal flexure actuators. 


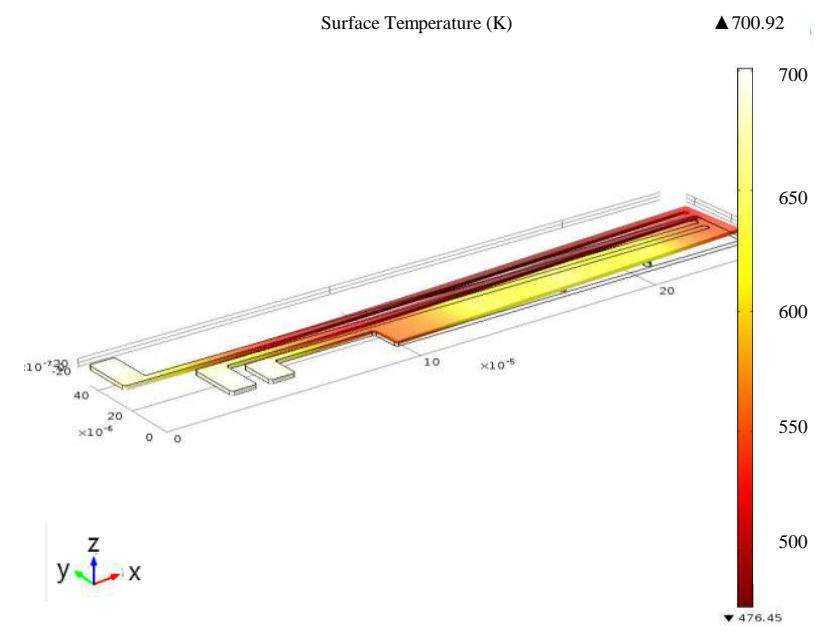

Fig. 6. Applied voltage 4 with length 240.

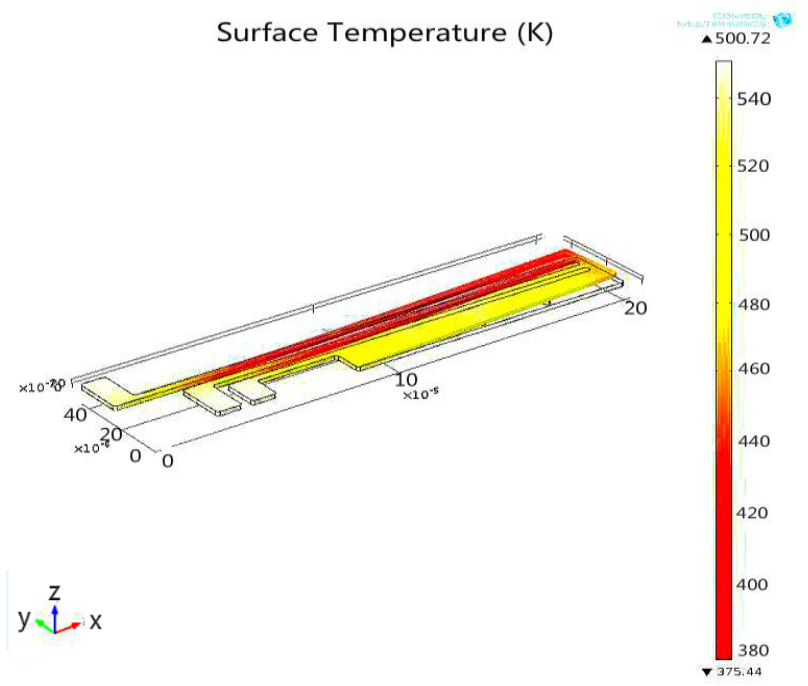

Fig. 7. Applied voltage 2 with length 200.

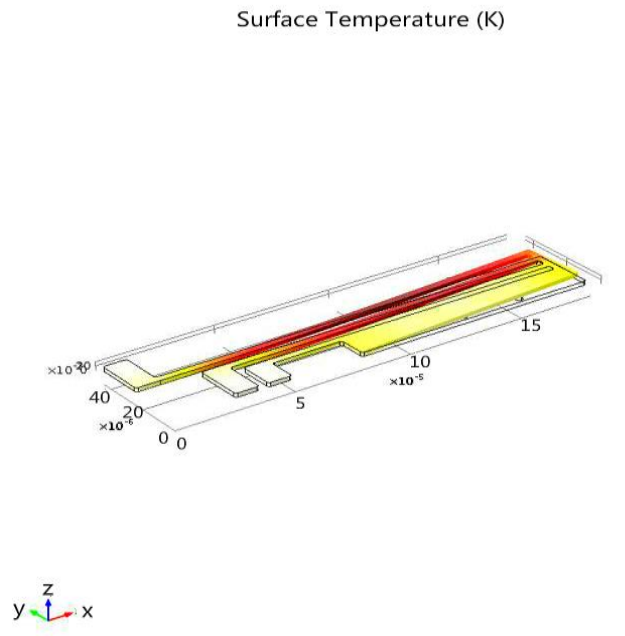

Fig. 8. Applied voltage 2 with length 180 .

\section{REFERENCE}

[1] H. K. Guckel et al., "Magnetic metal flexure actuators, Technical eligest, solid state sensor and actuator workshop," pp. 73-75, 1992.

[2] J. H. Comtois et al., "Micro actuators for surface- micromaching processes," in Proc. SPIE, vol. 2642, pp. 10-21, 1995.

[3] R. J. Bright, V. M. Comtois, and J. Arrarys "Thermal microactuators coupled to micro optical components actuators technology and applications," vol. 2865, 1997, pp. 74-82.
[4] J. H. Comtois et al., "Applications for surface micromachined polysiicon thermal actuators and arrays," Sensors and Actuators A, vol. 58, 1997, pp. 19-25.

[5] P. Hickey, "Analysis and optimal design of micro mechanical thermal actuators," M.A.sc thesis, Dalhousie University, Nova Scotia, CA, 2001.

[6] R. S. Chin et al., "Analysis of the optical dimension on the electro thermal micro actuators," J. Micromaching, vol. 12, pp. 291-296, 2002.

[7] Q. A. Huang and N. K. S. Lee, "Analytical modeling and optimization for a laterally-driven polysilicon," Microsyst. Tech., vol. 5, pp. 133-137, 1999.

[8] L. Lin and Chiao, "Electro thermal response of line shape microstructure," Sensors Actuators A, vol. 55, pp. 35-41, 1996.

[9] Y. J. Lai, C. Lee, C. Y. Wu et al., "Development of Electrothermal Actuator with Optimized Motion Characteristics," Jpn. J. Appl. Phys. vol. 42, part 1, no. 6B, pp. 4067-4073, June 2003.

[10] J. Mireles et al., "Design and Analysis of a MEMS Variable Capacitor using Thermal Actuators," Comp. Y Sist., vol. 10, no. 1, pp. 3-14, 2006.

[11] G. K. Fedder and R. T. Howe, "Thermal assembly of polysilicon microstructures," in Proc. IEEE Micro Electro Mechanical System Workshop, 1991, pp. 63-68.

[12] Y. J. Yang and K. Y. Shen, "Nonlinear heat-transfer macro modeling for MEMS thermal devices," Department of Mechanical Engineering, National Taiwan University, Taipei.

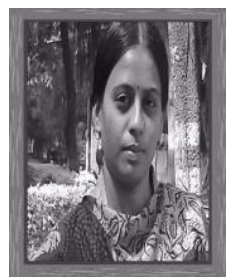

Girija M. Nimbal received her M.Sc degree from Karnataka State Women's University Bijapur, in 2009. She is currently a research scholar in Department of Electronics in KSWU Bijapur. Her research interests are MEMS numerical analysis, semiconductor device microprocessor, antennas, DSP.

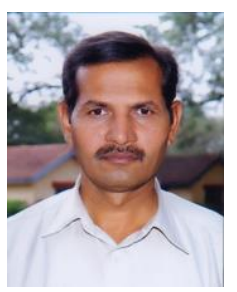

S. V. Halse is with Registrar Evaluation, Gulbarga University, Gulbarga. He is a fellow of Instrument Society of India, Indian Institute of Science. He has 21 years of teaching and research experience. He has been members of University Academic Council, BOS, BOE, BOA in Karnataka State Women's University, Bijapur. His interested areas are in fuzzy logic, digital electronics, networking, DSP, antenna, MEMS, and embedded systems.

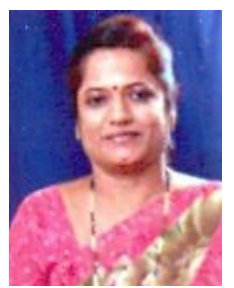

Rajeshwari S. Mathad received her M.Sc degree from Karnataka University Dharwad, she is the head of the Department of Electronics in Basaveshwar Science College Bagalkot. Recently she has submitted her $\mathrm{Ph} . \mathrm{D}$. thesis on "Some Studies on Active Filters uses Operational Transconductance Amplifier" to processing, her research area are in analog filter design, simulations of inductance, capacitance and resistance, using active devices.

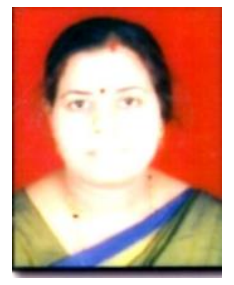

B. Jyoti received her M. Sc degree and M. Phil (Ph.D) P.G. Diploma in T.V. Tech \& P.G Diploma in computer applications, H. O. D. of Electronics Bi Bi Raza Degree College for Women, K.E. Society, Gulbarga.

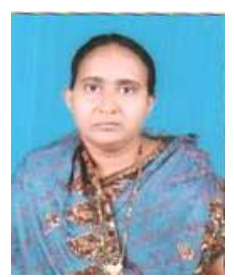

Rafia Begum is working as selection grade lecturer in Electrical \& Electronics Engg. Government Polytechnic, Bijapur. Her research interest area is in some studies on fuzzy logic applications. She has 13 years teaching experience. 
Computer Vision 
